\title{
INVESTIGANDO A APRENDIZAGEM DE PROFESSORES DE FÍSICA ACERCA DO FENÔMENO DA INTERFERÊNCIA QUÂNTICA*
}

\author{
Investigating Physics teachers' learning \\ on the quantum interference phenomenon
}

Fernanda Ostermann ${ }^{1}$ Sandra Denise Prado ${ }^{2}$

Trieste S. F. Ricci ${ }^{3}$

\begin{abstract}
Resumo: Analisa-se a evolução conceitual de 14 professores de Ensino Médio que foram estudantes, no $2^{\circ}$ semestre de 2005, de uma disciplina sobre Física Quântica (FQ) no Mestrado Profissional em Ensino de Física da UFRGS. Foi realizada uma análise de suas respostas acerca da interferência quântica em questionários especialmente desenvolvidos. Este estudo insere-se no âmbito de um projeto sobre Tópicos de Física Moderna e Contemporânea na formação de professores e já tem, como resultados a elaboração de um questionário sobre conceitos de FQ, construção e avaliação de uma unidade didática baseada em experimentos virtuais e o desenvolvimento de um software livre, do tipo "bancada virtual", que simula o fenômeno da interferência quântica em um aparato denominado Interferômetro de Mach Zehnder. A partir das sínteses das questões e da análise das respostas dos alunos, os resultados aqui relatados evidenciam aspectos de uma evolução conceitual em tópicos introdutórios de FQ.
\end{abstract}

Palavras-chave: Formação de professores. Interferência quântica. Avaliação da aprendizagem.

\begin{abstract}
An analysis of the conceptual evolution of 14 Physics Teachers attending a 4 credit discipline "Introductory Quantum Physics" from August to December 2005 is presented in this work. They were all regular students in the Professional Masters Degree Program in Instituto de Física (UFRGS). Our analysis focuses on answers to learning questionnaires on the particular phenomenon of quantum interference. This study is part of a current project concerned with the preparation of Physics Teachers in Topics of Modern and Contemporary Physics. The project has so far resulted in the elaboration of learning questionnaires on Quantum Physics, the elaboration and evaluation of a teaching unit based on virtual experiments and the elaboration of a freeware interactive software that simulates the quantum interference in the Mach-Zehnder Interferometer. From questions synthesis and student's answers, outcomes here related show aspects of a conceptual evolution in Quantum Physics introducty topics.
\end{abstract}

Key words: Teacher preparation. Quantum interference. Learning evaluation.

\footnotetext{
*Apoio parcial CNPq.

${ }^{1}$ Doutora em Ensino de Física; docente; coordenadora do Programa de Pós-Graduação em Ensino de Física; Departamento de Física, Instituto de Física, Universidade Federal do Rio Grande do Sul (IF/UFRGS). Porto Alegre, RS. <fernanda@if.ufrgs.br>

${ }^{2}$ Doutora em Física; docente; IF/UFRGS. Porto Alegre, RS. <prado@if.ufrgs.br>

${ }^{3}$ Doutor em Física; docente, IF/UFRGS. Porto Alegre, RS. <ricci@if.ufrgs.br>

${ }^{1}$ Instituto de Física, UFRGS

Campus do Vale, C.P. 15051

Porto Alegre, RS

$90.501-970$ 


\section{Introdução}

Neste trabalho foi analisado o processo de aprendizagem de 14 professores de Ensino Médio que, no $2^{\circ}$ semestre de 2005, foram estudantes de uma disciplina sobre Física Quântica (FQ) no Mestrado Profissional em Ensino de Física da Universidade Federal do Rio Grande do Sul (UFRGS). Este estudo insere-se no âmbito de um projeto sobre Tópicos de Física Moderna e Contemporânea na formação de professores (OSTERMANN e RICCI, $2005)^{4}$ e representa uma quarta etapa de esforços continuados numa pesquisa que envolveu, sobretudo, a elaboração de um questionário sobre conceitos de FQ (OSTERMANN e RICCI, 2004), a construção e avaliação de uma unidade didática baseada em experimentos virtuais (OSTERMANN e RICCI, 2005) e o desenvolvimento de um software livre, do tipo "bancada virtual", que simula o fenômeno da interferência quântica em um aparato denominado Interferômetro de Mach Zehnder - IMZ - (OSTERMANN, PRADO e RICCI, 2006). Discussões sobre interpretações da FQ foram também proporcionadas a partir de resultados obtidos no interferômetro (OSTERMANN e PRADO, 2005). Todos esses recursos, em permanente desenvolvimento, e um texto de apoio fazem parte do material didático do curso (RICCI e OSTERMANN, 2003).

Uma das principais motivações para a proposta do projeto está centrada na necessidade de preparar um curso introdutório à FQ que rompa com a abordagem tradicional geralmente adotada nos cursos ministrados na graduação e na pós-graduação. Essa abordagem freqüentemente enfatiza o emprego do formalismo matemático como principal recurso ou mesmo única ferramenta - principalmente em cursos de graduação - para a resolução de extensas listas de problemas. Uma premissa básica assumida no âmbito da formação inicial e continuada de professores do Ensino Médio é que uma abordagem mais conceitual e qualitativa da FQ, além de mais efetiva, é mais adequada, pois possíveis transposições didáticas para o Ensino Médio dependem fortemente de uma sólida formação conceitual, que só poderá ser construída se fundamentada em discussões epistemológicas e ontológicas (OSTERMANN e PRADO, 2005).

Uma revisão da literatura recente (OSTERMANN e RICCI, 2004), envolvendo artigos que discutem questões de ensino relacionadas ao tema e instrumentos construídos para a detecção de concepções de alunos e professores de Física sobre a FQ, mostrou que ainda são poucas as propostas de introdução de FQ no Ensino Médio e na formação de professores não apenas no Brasil ou na América Latina, devendo ser esse um tema recorrente em qualquer discussão que envolva tecnologias modernas, como leitores de $\mathrm{CD}$, luz laser, transistores e supercondutividade, para citar alguns exemplos. Também foi possível verificar que existe um número pequeno de pesquisas sobre concepções de alunos e professores em $\mathrm{FQ}$, o que justifica a análise aqui apresentada.

O presente artigo apresenta uma análise de respostas dos estudantes acerca da interferência quântica em questionários especialmente desenvolvidos para verificar aspectos de sua evolução conceitual. A questão de pesquisa central é: em que medida o uso de um software educacional tipo bancada virtual, que simula o funcionamento de um IMZ (RICCI, OSTER-

${ }^{4}$ Apoio parcial do CNPq e Edital Universal - 08/2004 - do CNPq. 
Investigando a aprendizagem de professores de Física...

MANN e PRADO, 2007; OSTERMANN, PRADO e RICCI, 2006) facilita a aprendizagem dos alunos acerca do fenômeno da interferência quântica, com base no conhecimento prévio da óptica ondulatória.

\section{Referencial teórico}

\section{A introdução da $F Q$ na perspectiva sociocultural}

As pesquisas sobre introdução de Física Moderna e Contemporânea (FMC) no nível médio e na formação de professores parecem ainda muito dirigidas pelo conteúdo, sem maiores considerações sobre fundamentos teóricos na área de educação.

Apesar de representar um guarda-chuva que tem dado origem a diferentes propostas educativas, o construtivismo tem sido pouco utilizado para orientar o desenvolvimento de materiais didáticos que incorporem temas de FMC. A abordagem construtivista é hoje predominante no meio educacional, mas não uma tendência única refletida nos materiais didáticos, mesmo porque a idéia de construção do conhecimento está presente na obra de vários autores, como Piaget, Vygotsky, Paulo Freire e Freud, entre outros e, dependendo de qual deles seja o referencial eleito, configura-se uma proposta pedagógica um pouco diferenciada.

Apesar das diferenças entre as concepções teóricas sobre o construtivismo, há elementos comuns fundamentais. Talvez o mais marcante seja a consideração do indivíduo como agente ativo de seu próprio conhecimento, o que, no contexto educativo, desloca a preocupação do processo de ensino (visão tradicional) para o de aprendizagem. Na visão construtivista, o estudante constrói representações de acordo com suas experiências e seu conhecimento anterior, sobre os quais novos conhecimentos são edificados. Apesar de individual, este processo se dá pela interação com os outros e com a realidade. Em particular, a perspectiva sociocultural na pesquisa em Educação em Ciências tem indicado um caminho promissor para a superação da predominância do caráter individual e cognitivista, tanto no que se refere à aprendizagem do aluno quanto à formação de professores. Essa abordagem concebe ciência, educação em ciências e pesquisa como atividades sociais humanas inseridas num sistema cultural e institucional, o que implica atribuir um peso teórico significativo ao papel da interação social (VYGOTSKY, 1989, 1984), vendo-a como necessária e não meramente auxiliar ao processo de aprendizagem (LEMKE, 2000). Para Vygotsky (1984), o que caracteriza a psicologia humana é o fato de que o desenvolvimento se dá pela "internalização das atividades socialmente enraizadas e historicamente construídas" (p. 64). O aprendizado humano pressupõe uma natureza social específica, na medida em que todas as funções intelectuais superiores originam-se das relações entre indivíduos.

Um dos aspectos mais importantes da perspectiva sociocultural é a primazia da linguagem no entendimento dos processos humanos (WERTSCH, 1991). Ao compreender os processos educativos atribuindo à linguagem um papel constitutivo na elaboração conceitual e não meramente uma dimensão comunicativa ou de instrumento, o referencial sociocultural muda radicalmente o olhar dos pesquisadores, que passam a integrar, necessariamente, a mediação do outro e de ferramentas culturais. Nesta perspectiva, a pesquisa aqui apresentada busca enfocar, principalmente, a construção de significados na interação verbal entre sujeitos que, 
trabalhando em duplas e com a ajuda de membros mais competentes (no caso, o professor), constroem significados cada vez mais ricos e culturalmente válidos sobre o fenômeno da interferência quântica, a partir do uso de uma ferramenta cultural em particular - o software IMZ. Considerar o experimento virtual como ferramenta cultural permite problematizar em que medida sua mediação conforma a ação educativa.

Do ponto de vista da introdução da FQ, assumiu-se como pressuposto teórico básico a concepção de que o novo conhecimento é construído pelo estudante a partir de seu conhecimento prévio e, também, pela interação com parceiros mais capazes ou mais maduros (VYGOTSKY, 1989, 1984). Isso levou à adoção da chamada "vertente metodológica espanhola" (GIL e SOLBES, 1993), que defende que a FMC seja ensinada de forma relacionada à Física Clássica, seja numa relação de continuidade ou de ruptura. Neste estudo, essa escolha significou utilizar a Óptica Ondulatória como espécie de "porta de entrada" para o mundo quântico, mediante abordagem de analogias entre situações da Óptica e Mecânica Quântica (MQ) e, também, da exploração de semelhanças formais entre as duas teorias. O papel destacado da Óptica Ondulatória na concepção da unidade conceitual, como "pano de fundo" clássico para a abordagem da Mecânica Quântica, está baseado na própria formulação histórica da Mecânica Ondulatória por Schrödinger, em 1925-26 (OSTERMANN e RICCI, 2005).

Deve ser notado que a estratégia adotada representa um rompimento significativo com a abordagem tradicional, uma vez que esta segue rigorosamente a cronologia histórica da FQ, começando com a "velha teoria quântica", para, então, ensinar a "nova" teoria, geralmente em sua versão ondulatória. Ou seja, na abordagem tradicional costuma-se explorar modelos diretamente inspirados na Mecânica Clássica de partículas para depois introduzir um modelo eminentemente ondulatório (Mecânica Ondulatória). Na concepção da unidade conceitual, preferiu-se explorar, desde o início do aprendizado, as analogias quase que naturais entre a Óptica Ondulatória clássica e a Mecânica Ondulatória de Schrödinger, sem passar pela "velha teoria quântica". Em relação a outras abordagens desenvolvidas (OSTERMANN e RICCI, 2005, 2004), foram exploradas, também, diferentes interpretações da FQ, além da ortodoxa (Escola de Copenhague).

\section{A formação do professor de Física e a introdução da FMC no ensino médio}

Recentemente, tem sido admitido cada vez mais um corte epistemológico entre o conhecimento de Física com o qual o licenciando lida na universidade e o que ele terá que ensinar no Ensino Médio. A pouca discussão do significado conceitual e da interpretação qualitativa do formalismo matemático nos cursos de Física, essencial para o professor de nível médio, e a falta de relação desse conteúdo com a realidade escolar, induzem o estudante a deixar de lado o que foi abordado nos cursos de licenciatura e ter como referência o conteúdo dos livros didáticos de nível médio. A possibilidade de tirar proveito do aprofundamento do conteúdo físico, na formação, relacionando-o interdisciplinarmente a conteúdos pedagógicos e aos resultados das pesquisas em ensino de Física para gerar novas metodologias de ensino tem sido perdida. Em particular, em relação à temática da FMC no Ensino Médio, essa ruptura epistemológica ocorre de forma mais aguda na formação de professores, à medida que o isomorfismo de conteúdo (em analogia ao princípio do isomorfismo metodológico defendido por PORLÁN e RIVERO, 1998) não tem sido respeitado. 
Investigando a aprendizagem de professores de Física...

Em analogia ao princípio do isomorfismo metodológico, o isomorfismo referente ao conteúdo da FMC implica que a própria formação de professores deverá contemplar, desde seu início, a atualização curricular, passando a priorizar conteúdos mais atuais da Física, "enxugando" o tempo dedicado aos temas clássicos. Sem respeitar esse princípio não se pode esperar que a renovação ocorra nas escolas.

No que diz respeito à introdução da FMC no Ensino Médio, é reconhecida a pouca tradição didática desses conteúdos mais atuais de Física. Tanto no exterior como no Brasil, essa linha de investigação tem focalizado bem mais o conteúdo específico, em detrimento de aspectos metodológicos e fundamentos teórico-epistemológicos, em suas publicações, o que acaba representando mais um obstáculo para a construção do conhecimento pedagógico do conteúdo da FMC pelos professores.

Do ponto de vista das políticas públicas, a Lei de Diretrizes e Bases da Educação Nacional, de 20 de dezembro de 1996 (BRASIL, 2006), destaca a FMC a partir de um possível objetivo para o ensino formal: o destaque dado à educação tecnológica básica, à compreensão do significado da ciência e ao domínio dos princípios científicos e tecnológicos que presidem a produção moderna. Particularmente no que se refere à área de "Ciências da Natureza, Matemática e suas Tecnologias", na qual se insere a disciplina de Física, os parâmetros curriculares nacionais (BRASIL, 2006), sem mencionar uma lista de conteúdos a serem trabalhados no Ensino Médio, ressaltam que as disciplinas científicas têm omitido os desenvolvimentos realizados do século XX em diante e propõem uma atualização de conteúdos que proporcione aos alunos as condições para desenvolver uma visão de mundo atualizada. Já temas de FMC estão explicitamente expressos em muitos dos aspectos das "Orientações Educacionais Complementares aos Parâmetros Curriculares Nacionais”, PCN+ (BRASIL, 2002).

A integração entre diferentes áreas da Física é também uma preocupação das novas orientações curriculares, uma vez que propõem uma releitura das áreas tradicionalmente trabalhadas, estabelecendo que competências e habilidades se desenvolvem por meio de ações concretas, que se referem a conhecimentos, a temas estruturadores. Nesse caso, tópicos de FMC podem se inserir, naturalmente, no tema estruturador "Matéria e Radiação" (PCN+), no qual está contemplada a necessidade de proporcionar aos estudantes uma compreensão mais abrangente sobre como se constitui a matéria e sobre os diferentes modelos de explicação propostos. Vê-se, portanto, que também do ponto de vista da nova legislação há uma tendência de promover a renovação curricular, buscando no conhecimento científico recente subsídios para que o aluno venha a compreender o mundo criado pelo homem atual. A formação (inicial e continuada) de professores deverá contemplar essas discussões, sob pena de condenar o ensino da FMC ao que está proposto na maioria dos livros didáticos de Física para o Ensino Médio. Pinceladas da "velha" FQ com alguns raros tópicos de Relatividade Restrita, são, de maneira geral, os temas de FMC abordados nos últimos capítulos das obras disponíveis no mercado brasileiro.

Longe de ser um tema que pode ser resolvido com uma receita que inclua apenas uma lista de conhecimentos, a formação do professor de Física é uma linha que requer pesquisa sistemática que não despreze seu caráter complexo. Parece que deveríamos estar sempre à frente de uma tensão essencial entre reconhecer sua complexidade e a postura de não nos sentirmos imobilizados diante dela. Resultados de estudo realizado no Brasil, apontando o desencontro entre pesquisa e prática docente do professor de Física, também são constatados 
na literatura internacional e podem orientar ações que busquem superar esse distanciamento (REZENDE e OSTERMANN, 2005).

Segundo Rezende e Ostermann (2005), mesmo quando o problema enfrentado pelo professor para ensinar Física é contemplado na pesquisa, os aspectos investigados não são preocupação do professor, além do que, as condições concretas de trabalho do docente na escola pública não são levadas em consideração. É necessário que os investigadores em Educação em Ciências invistam em trabalhos conjuntos com professores de Física do Ensino Médio na pesquisa de novos objetos de estudo que sejam de interesse de ambos.

De acordo com Briscoe (1991), a aproximação entre pesquisa e prática somente pode ocorrer quando o professor se afasta do papel de mero consumidor para passar a ser um agente ativo de mudança. A integração entre universidade e conhecimento dos professores pode, assim, romper a linha divisória existente entre pesquisadores acadêmicos e professores (ZEICHNER, 1998), criando convergências entre a pesquisa e o ensino. Um contexto para fomentar essa aproximação são os cursos de mestrado profissional em ensino de Física, nos quais os professores, em parceria com pesquisadores, podem tomar objetos de estudo mais adequados à prática docente. Neste contexto de formação foi desenvolvida a pesquisa que será descrita na próxima seção.

\section{Metodologia}

O estudo sobre a evolução conceitual acerca do fenômeno de interferência quântica dos 14 estudantes envolvidos nessa nova abordagem da FQ foi feito a partir de dois instrumentos especialmente elaborados. Um questionário inicial com 17 questões abertas (além de dez itens iniciais para identificar a formação prévia dos estudantes) foi aplicado num primeiro momento, na primeira aula. Cabe ressaltar que os estudantes foram colaboradores voluntários neste estudo, visto que souberam desde o primeiro contato com o professor que esse questionário, assim como outro, posterior, seria analisado como parte de um projeto de pesquisa. Ao final do semestre, como última atividade da disciplina foi aplicado um outro questionário, com 15 questões de FQ versando sobre os principais temas discutidos e especial ênfase nos resultados dos experimentos virtuais.

A análise das respostas dos estudantes aos questionários inicial e final, destacadas a seguir, envolveu o levantamento inicial de todas as respostas dadas e, em uma etapa posterior, a organização das mesmas na busca de evidências acerca da evolução conceitual em alguns temas específicos abordados neste estudo. Das 17 questões do questionário inicial serão analisadas as que se referem ao fenômeno de interferência quântica e as que abordam aspectos cruciais da óptica ondulatória para o entendimento da FQ:

Q7. A figura 1 é uma vista superior do aparato usado pelo médico Thomas Young - em 1801 - para realizar seu famoso experimento da fenda dupla com a luz. $\mathrm{S}_{0}$ é uma pequena fenda simples em um anteparo, e $S_{1}$ e $S_{2}$ constituem uma fenda dupla, sobre um segundo anteparo, situado entre o primeiro e a tela. (i) $\mathrm{O}$ que foi observado por ele na tela que comprovava fortemente a teoria ondulatória da luz? (ii) Qual a finalidade do 
Investigando a aprendizagem de professores de Física...

anteparo com a dupla fenda? (iii) Qual a finalidade do anteparo com apenas uma fenda? (iv) Que fenômenos ondulatórios "estão por trás" do resultado observado na tela?

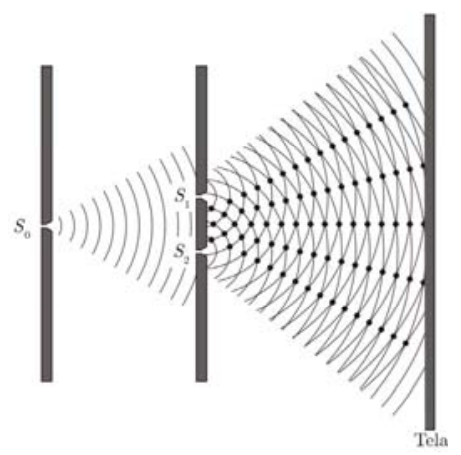

Figura 1. Vista superior do aparato usado pelo médico Thomas Young em 1801.

Q8. A partir do experimento de Young e de outros que se seguiram na primeira metade do século XIX, a idéia de que a luz é algum tipo de onda foi se firmando. Durante a segunda metade desse século, acreditou-se cada vez mais e foi comprovado, sistematicamente, a partir do trabalho experimental de Hertz (1887), que a luz pode ser considerada uma onda eletromagnética. No entanto, a partir do trabalho de Einstein sobre o efeito fotoelétrico (1905), começou a vingar uma renovada teoria corpuscular, que considerava agora a luz como sendo formada por "corpúsculos", denominados, mais tarde, fótons. Considere novamente o experimento da fenda dupla. (i) Se ele fosse realizado com um feixe luminoso monocromático tão fraco que apenas um único fóton incidisse no anteparo de cada vez (feixe monofotônico), o que você acha que seria observado na tela após algum tempo decorrido?

Q9. Suponha agora que realizássemos o experimento da fenda dupla com um feixe de elétrons substituindo o feixe luminoso (e que retiramos o anteparo de fenda única do aparato da figura 1). Suponha também que a superfície da tela tenha sido pintada com um material sensível ao elétron, cujo impacto produz um pequeno ponto na tela. O que você acha que seria observado?

Q10. Na questão anterior, o que você acha que seria observado na tela se o feixe luminoso monocromático fosse substituído por um feixe mono-energético de elétrons (todos de mesma energia), tão pouco intenso que apenas um único elétron incidisse no anteparo de fenda dupla? (OBS: Considere novamente que o anteparo de fenda única tenha sido retirado, e que a tela tenha sido pintada com material sensível aos impactos de elétrons.) 
Q11. Costuma-se considerar elétrons, prótons, nêutrons e outros objetos microscópicos como partículas. (i) Em sua opinião, quais são as propriedades corpusculares características e essenciais desses objetos? (ii) De que maneira essas propriedades se manifestam no mundo real?

Q12. Você diria que os objetos microscópicos mencionados na questão anterior poderiam também exibir, sob certas circunstâncias, propriedades tipicamente ondulatórias? De que maneira você acha que tais propriedades se manifestam no mundo real?

Q15. A Mecânica Quântica, de Schrödinger, Heisenberg, Dirac e outros, trouxe novas idéias sobre o mundo microscópico. Em particular, permitiu uma melhor compreensão da noção conhecida como Dualidade Onda-Partícula, originada dos trabalhos pioneiros de de Broglie, Compton e outros na década de 1920. (i) Qual seria sua versão pessoal do enunciado da dualidade-partícula? (ii) Qual a relação famosa que expressa matematicamente a dualidade onda-partícula? (iii) Cite um exemplo de experimento capaz de servir como comprovação da dualidade onda-partícula. (Adaptado de questão do Exame Nacional de Cursos 2000.)

Das 15 questões do questionário final, serão analisadas as que seguem:

Q1. Você já comentou algum(alguns) dos conceitos que aprendeu nesta disciplina com professores ou alunos da(s) escola(s) em que trabalha? Em caso afirmativo, o quê especificamente?

Q2. Você leu os capítulos recomendados do "Alice no País do Quantum"? Em caso afirmativo, qual a parte que lhe despertou mais interesse? Como você relaciona o que é discutido nessa parte da obra com o que foi abordado em nosso curso?

Q3. Se você pudesse exemplificar a Física Quântica através de um "experimento" (real ou imaginário), qual você escolheria? Justifique sua resposta.

Q6. Use pelo menos um dos três experimentos em regime monofotônico: i) Abertura única, ii) Fenda Dupla e iii) Interferômetro de Mach-Zehnder, para comentar, discutir, exemplificar, justificar, uma a uma, as seguintes afirmações:

a) A Mecânica Quântica só fornece predições estatísticas - seus resultados são probabilísticos, no sentido de que são verificados para um ensemble de partículas.

b) Se o atributo posição de um objeto quântico for bem definido, o padrão de interferência é destruído.

c) Os objetos quânticos são partículas "convencionais", pois sua detecção é sempre puntiforme (localizada).

d) O processo de medida provoca o colapso do estado em um dos auto-estados da grandeza que está sendo medida. O colapso é aleatório, conferindo à Mecânica Quântica um caráter não-determinista. 
Investigando a aprendizagem de professores de Física...

Q12. Se você tivesse que optar por uma das quatro interpretações da Mecânica Quântica (vistas no curso), qual você escolheria? Justifique sua escolha.

\section{Descrição das aulas}

Os encontros eram semanais, às segundas-feiras, entre $8 \mathrm{~h} 30 \mathrm{~min}$ e $12 \mathrm{~h} 30 \mathrm{~min}$. A sala de aula oferecia recurso áudio-visual e eram freqüentes as buscas na rede por software ou textos como recurso auxiliar. O curso foi também dividido em três partes: a primeira, dita módulo conceitual, um segundo módulo formal e um terceiro, de seminários. A descrição das aulas refere-se exclusivamente ao primeiro módulo.

1) Aula I: aplicação do questionário inicial sobre noções de Mecânica Quântica; discussão das bases históricas da Mecânica Quântica e da Óptica Ondulatória - difração e interferência; cálculo da posição dos máximos e mínimos na intensidade do padrão da fenda dupla usando soma de ondas; visita ao laboratório de ensino para demonstração de experiências sobre fenda única e fenda dupla;

2) Aula II: discussão do efeito fotoelétrico e o conceito de fóton; relação entre energia do fóton e freqüência; efeito compton;

3) Aula III: dualidade onda partícula e a relação de de Broglie; padrão de interferência para o fulereno; fenda dupla para fótons; fenda dupla para elétrons;

4) Aula IV: introdução das interpretações da Mecânica quântica explorando a fenda dupla para fótons e para elétrons. Foram trabalhadas quatro interpretações (OSTERMANN e PRADO, 2005): a interpretação ondulatória (inicialmente proposta por Schrödinger), a da complementaridade (associada a Bohr), a interpretação das variáveis ocultas (de de Broglie e Bohm) e a interpretação de muitos mundos (de Everett). Sugestão para que os alunos explorassem em casa o programa para fenda dupla (MÜLLER e WIESNER, 2002); discussão da partícula livre e pacotes de onda (equação de Schrödinger para partícula livre); introdução da interpretação da probabilidade de Max Born;

5) Aula V: debate sobre as quatro interpretações no experimento da fenda dupla; apresentação da equação de Schrödinger dependente do tempo e independente do tempo; pacotes de onda e princípio da incerteza. Foram sugeridos alguns links, principalmente para que os alunos observassem o que seria a evolução temporal de um pacote de onda. Essa aula foi basicamente conceitual, mas a Equação de Schrodinger foi bastante explicitada. Vale ressaltar que, embora esse módulo fosse puramente conceitual, nenhum conceito foi discutido sem que fosse também colocada alguma equação no quadro-negro. A idéia que acabou vigorando à medida em que as aulas prosseguiam, foi a de que uma maior integração entre o formalismo matemático e os fundamentos conceituais também é importante;

6) Aula VI: discussão da teoria da medida e da medida nula - teste de bombas de Eliztur-Vaidman (PESSOA JR., 2003) - que introduzem o IMZ; discussão do postulado do colapso do pacote de onda; abordagem do poço infinito (energia de ponto zero, quantização da energia, energia mínima de confinamento) e dos estados estacionários e a idéia da superposição de estados; apresentação da relação de incerteza energia-tempo, posição-momentum;

7) AulaVII: trabalho orientado com a simulação de um Interferômetro de MachZehnder (IMZ) em sala de aula (OSTERMANN, PRADO e RICCI, 2006). Os alunos traba- 
lharam com o software do IMZ segundo um roteiro especialmente elaborado. Essa aula ocorreu no laboratório de ensino e havia disponibilidade de um computador por aluno. Os alunos trabalharam em sala, mas levaram o roteiro para terminar em casa. (O trabalho foi entregue na semana seguinte, corrigido, comentado e os alunos tiveram chance de entregá-lo novamente para uma segunda correção);

8) Aula VIII: os alunos trouxeram a primeira versão das respostas do roteiro do IMZ. Um segundo roteiro para o simulador da fenda dupla (MÜLLER e WIESNER, 2002) foi entregue aos alunos para que eles trabalhassem com o software em casa. Nessa aula, discutiu-se com mais detalhamento e com base nas interpretações da MQ o teste de Bombas de Eliztur-Vaidman (PESSOA JR., 2003), a teoria da medida e o próprio IMZ. A discussão foi bastante acalorada, em virtude do trabalho dos alunos durante a semana com o software. Como ficou claro que muitas das questões colocadas pelos alunos ainda eram de deficiências em relação ao fenômeno ondulatório, foi sugerido que eles explorassem links para difração em fenda única para a luz e difração em fenda única com partículas;

9) Aula IX: entrega do roteiro do IMZ e comentário geral das respostas. Todas as questões foram discutidas. Alguns alunos pediram para entregar o roteiro da fenda dupla na próxima aula, por "terem percebido" que estavam "equivocados" em alguns pontos - tudo isso devido à discussão do IMZ. Essa aula foi toda de discussão das mais diversas dúvidas sobre colapso, interpretações, probabilidades, dualidade onda-partícula. Os alunos debateram sobre as interpretações;

10) Aula X: os alunos entregaram o roteiro da fenda dupla. Houve discussão sobre as dúvidas que eles ainda tinham em relação ao IMZ e à fenda dupla, com possíveis comparações entre a fenda dupla e o IMZ. Foi sugerido o texto do Max Tegmark e John Archibald Wheeler (100 anos de mistérios quânticos) para leitura. (Reprodução do artigo original do link da Scientifc American). Os postulados da MQ foram enunciados;

11) Aula XI: discussão do roteiro da fenda dupla.

\section{Resultados}

Seguem trechos das respostas (destacadas em itálico), como exemplos (os nomes foram omitidos e substituídos por uma ou duas letras, entre parênteses, após o respectivo trecho da resposta). Ao final de cada questão, uma síntese das mesmas:

\section{Questionário inicial: \\ Q.7}

i) interferência construtiva e destrutiva com a formação de máximos e mínimos (Ra; Z; E; Ls); interferência construtiva $(\mathrm{Ca})$; máximos e mínimos $(\mathrm{Lz})$; manchas escuras onde se teria interferência de duas ondas (Mr).

ii) obter ondas em fase (Ra); para observar a separação da onda (Ca); comprovar superposição das ondas $(\mathrm{Z})$; obter duas fontes de onda $(\mathrm{E} ; \mathrm{Mr} ; \mathrm{Pl} ; \mathrm{Tt})$; para haver interferência. construtiva $(\mathrm{Lz})$; promover difração (Ls; $\mathrm{Cl})$; sem interferência $(\mathrm{Ro})$; verificar interferência $(\mathrm{Mu})$; 
Investigando a aprendizagem de professores de Física...

iii) mostrar a difração da luz (Ra; Lz; Ls; $\mathrm{Mr} ; \mathrm{Pl} ; \mathrm{Mu})$; para passar uma única onda (Ca; Tt); obter um único feixe de ondas em fase (E); gerar interferência (Cl); colimar um feixe de luz (Ro);

iv) difração e interferência (Ra; E; Ls; $\mathrm{Mr} ; \mathrm{Ag} ; \mathrm{Pl} ; \mathrm{Mu})$; interferência - superposição da onda (Ca); interferência (Lz; Cl); difração (Ro); difração e dispersão (Tt).

Síntese da Q.7: os alunos, em geral, admitiam a formação de um padrão de interferência que comprova a teoria ondulatória da luz. Poucos, no entanto, conheciam a finalidade da fenda única e da dupla no experimento de Young e apenas metade reconheceu os fenômenos da difração e da interferência nesse arranjo experimental. No entanto, ficou claro, pelo conjunto das respostas da questão, que os alunos devem ter estudado anteriormente difração e interferência da luz, muito embora não tenham bom domínio do fenômeno ondulatório. Nenhum aluno respondeu satisfatoriamente a todos os quatro itens da questão.

\section{Q.8}

Dois pontos luminosos, evidenciando o caráter corpuscular e, ao mesmo tempo, ondulatório (Mu); Incidência na tela de duas partículas de menor energia ( $\mathrm{Tt})$; difração (Ro); mais de um ponto luminoso $(\mathrm{Cl}) ;$ o mesmo da onda (Ls; Lz; E; Z; Ca); apenas o ponto onde o fóton incide, mais probabilidade de colisão em alguns pontos do que em outros (Ra).

Síntese da Q.8: apenas cinco alunos reconheceram a formação do mesmo padrão da questão 7 , muito embora não tenham respondido satisfatoriamente a todos os itens da questão anterior.

\section{Q.9}

Franjas de interferência com máximos e minimos (Ra; E; Mr; Cl); Vários pontos (Ca; Z; Lz ); um ponto (Ls); difração (Ro); chegada de dois fótons na tela (Tt); luminosidade da tela provocada pela mudança de niveis de energia dos elétrons da superficie da tela $(\mathrm{Mu})$.

Síntese da Q.9: apenas quatro admitiram que ocorra o mesmo padrão quando se opera com um feixe de elétrons. Desses, um não respondeu satisfatoriamente à questão $8 \mathrm{e}$ outro respondeu erradamente aos itens ii e iii da questão 7.

\section{Q.10}

Um ponto luminoso (Mu; Ls; Ra); zonas escuras e claras também (Cl; E); um ponto indeterminado $(\mathrm{Lz})$; vários pontos $(\mathrm{Ca})$.

Síntese da Q.10: apenas dois alunos apontaram para a formação do padrão de interferência. Um deles, $\mathrm{Cl}$, não respondeu à questão 8 (parece não relacionar a fenda dupla para elétrons com a fenda dupla para fótons). Sete não responderam à questão.

\section{Q.11}

i) massas e cargas (Ra; $\mathrm{Mr} ; \mathrm{Cl}$; $\mathrm{Ro} ; \mathrm{Mu})$; dimensões (E); incidem em um corpo arrancando ou liberando energia (Lz;); se comportam como onda e como particula $(\mathrm{Tt})$; 
ii) através de interações de atração e repulsão $(\mathrm{Ra})$; de maneira estática $(\mathrm{E})$; na constituição dos corpos macroscópicos e nos fenômenos eletromagnéticos $(\mathrm{Mr})$; correntes elétricas, equipamentos (Cl); comportam-se como onda e como particula (Tt); em termos de função de onda, de acordo com a probabilidade de ocorrência dos eventos $(\mathrm{Mu})$.

Síntese da Q.11: no item i, seis não responderam e cinco apontaram as propriedades "massa" e "carga" como características das partículas. Nenhuma menção às grandezas naturais envolvidas na dualidade onda-partícula como localidade para partícula (posição e velocidades compatíveis) e não-localidade para ondas (posição e velocidade incompatíveis) foi feita. Nenhuma menção aos termos freqüência ou comprimento de onda para ondas ou momentum para a partícula. No item ii houver diversidade de respostas.

\section{Q.12}

Sim (Mu; Lz; E; Ra); Sim - feixe de luz como bolinhas (Tt); Sim - de forma indireta (Ro); Sim interferência construtiva e negativa no experimento de dupla fenda $(\mathrm{Cl})$.

Síntese da Q.12: apenas um estudante admitiu que esses objetos microscópicos possam exibir padrão de interferência. Sete alunos não responderam.

\section{Q.15}

i) Às vezes, as particulas se comportam como onda, às vezes, como particulas, depende do contexto (Ra; $\mathrm{Mr} ; \mathrm{Cl} ; \mathrm{Tt}$ ); Toda partícula tem comportamento de onda e toda onda tem comportamento de partícula, dependendo da experiência (E;) a luz, ou o elétron se comportam como onda ou partícula (Lz); a luz,pode ser onda ou partícula, depende da situação analisada (Ls); propriedade da matéria (Ro).

ii) Eq. de Schrodinger (Ra).

iii) Fenda dupla de Young (Ra; $\mathrm{Tt})$; feixe de elétrons sobre duas fendas (Cl); difração de elétrons (Ro); difração de raios $X(\mathrm{Mu})$.

Síntese da Q.15: no item i, seis não responderam e quatro responderam, em linhas gerais, que "às vezes, as particulas se comportam como onda, às vežes, como particulas". No item ii, 13 não responderam e um apontou a Equação de Schrodinger. No item iii, nove não responderam e três deram exemplos corretos, como: "difração de elétrons, difração de raios $X$ ou fenda dupla com elétrons".

Antes de qualquer conclusão acerca dos resultados verificados no questionário inicial, é necessário ressaltar que os 14 alunos tinham formação universitária na área das Ciências Exatas, mais especificamente, 13 eram Licenciados em Física e apenas um era Licenciado em Matemática. Pelas respostas ao primeiro questionário pôde-se observar que a maioria teve contato prévio com o tema interferência e difração da luz, especialmente sob a óptica da fenda dupla. Os alunos, em sua maioria, foram capazes de colocar os termos-chave como superposição de duas ondas para definir interferência e padrão de franjas como resultado de uma interferência, mas nenhum conseguiu responder de forma coerente a todas as questões referentes à interferência. Essa situação também se repete nas questões acerca da dualidade 
Investigando a aprendizagem de professores de Física...

onda-partícula da FQ. Alguns citaram que um fóton ora se comporta como onda, ora se comporta como partícula, mas não fizeram nenhum paralelo entre o comportamento do fóton com o comportamento do elétron na fenda dupla, por exemplo.

Essa situação de muita informação e pouca reflexão sobre a interferência nos levou a retomar os conceitos centrais da óptica ondulatória para somente depois trabalhar, sem rupturas, na transposição dos conceitos clássicos para a FQ. Quando o aluno reconhece um padrão de interferência e consegue entender claramente o que o gerou e em que condições a interferência acontece, então a abstração requerida pela FQ como identificação ou analogia da intensidade (proporcional à amplitude) da onda clássica com densidades de probabilidade já não parece tão inacessível ao estudante. É o que se verifica no segundo questionário.

\section{Questionário final: \\ Q.1}

Sim. De acordo com uma das escolas da Quântica, a dualista, a particula ora se comporta como onda, ora como partícula, porém não com as duas características ao mesmo tempo. Ex: no experimento de fenda dupla, explicamos a formação de franjas de interferência se imaginarmos as partículas como ondas distribuidas no espaço que sofrem interferência e difração e que ao colidirem no anteparo sofrem um "colapso" da função tornando-se bem localizadas e dessa forma tendo características de particulas (Ra); Fenda dupla e Mach-Zehnder (Pl); colapso da função de onda quando queremos verificar o caminho percorrido pelos entes quânticos; o fato de que elétrons e fótons interagem consigo mesmo (Cl); Comportamento dual da luz (Ls); gato na caixa (Ls; $\mathrm{Tt}$ ); caráter não determinístico da $M Q(\mathrm{Ls}) ;$ Interpretações da FQ (Mr).

Síntese da Q.1: a maioria dos estudantes se reporta ao IMZ ou à fenda dupla para comentar conceitos de MQ que foram discutidos com professores ou alunos de sua escola, exemplificando de forma correta, como na resposta de Ra.

\section{Q.2}

Caráter dual de objetos quânticos (Ra); Superposição quântica (Z; Pl; Ca; Ag) e colapso (Z; Lz); Linguagem adotada pelo autor $=$ proposta de abordagem mais acessivel (Ro); Diferentes interpretações da MQ dentro da Escola de Copenhague (Mu); Fenda dupla com elétrons (Mr; Ls), mas poderia ser explorada a fenda única e o fato de o elétron interferir com ele mesmo (Mr); Paradoxo do gato (Lz).

Síntese da Q.2: a diversidade de respostas é natural nesta questão. Os alunos tiveram oportunidade de ler sobre temas que já haviam estudado ou que estavam sendo vistos em sala de aula com uma 'roupagem' diferente, fazendo com que pensassem sobre o assunto a partir de uma nova perspectiva. Por isso, temas que são obrigatórios nas disciplinas introdutórias de FQ, como o caráter dual de objetos quânticos ou a superposição quântica, despertaram interesse em Ra e em Z, por exemplo. Entre as respostas, com o paradoxo do gato Lz citou um tópico pouco abordado ou pouco entendido nas fases introdutórias de MQ. A coletânea de respostas pode indicar a carência de leitura dos alunos e a pouca reflexão sobre os novos conceitos vistos durante a graduação. 
Q.3

Interferômetro de M-Z, pois favorece o entendimento da dualidade onda-partícula (Ls) bem como o caminho escolbido pelo fóton (Ag). Pois quando há medida, há colapso da função de onda, não havendo mais interferência destrutiva ou construtiva. Na fenda dupla isto não é tão evidente pois nem todos os elétrons são percebidos pela lâmpada (Lz); Interferômetro de $M-Z$, pois há padrão de interferência após vários experimentos monofotônicos e o padrão corpuscular quando retiramos o segundo semi-espelho ou quando colocamos um detector em um dos braços (Ca). Pois se explora os conceitos mais pertinentes da MQ (Pl). Dualidade, superposição quântica (Ra); Fenda dupla, pois mesmo em regime monofotônico/eletrônico há padrão de interferência; o elétron interage com ele mesmo (Cl). Pois mostra propriedades ondulatórias de difração e interferência não só da luz como de partículas atômicas e subatômicas (E); Fenda dupla, pois é o mais próximo da FC (Ma; Mr); comparação entre gunballs e objetos quânticos (Ma); a tentativa de "monitorar" o elétron destrói a interferência (Mu). Pois apresenta o caráter dual da matéria (Tt e Z); Radiação do corpo negro (Ro).

Síntese da Q.3: um aluno destacou, erradamente, um exemplo de experimento da "velha MQ" - radiação de corpo negro. A maioria citou o IMZ e a fenda dupla com várias explicações corretas, como se pode ver na resposta de $\mathrm{Ca}, \mathrm{Cl}$, E. As respostas, no entanto, foram bastante 'econômicas'. Os alunos não demonstraram confiança na elaboração de respostas próprias para as questões - medo de 'falar demais e errar', mas o progresso foi evidente. Eles fizeram menção acertada com relação à fenda dupla e também ao IMZ - os softwares trabalhados em sala de aula e em atividades extra-classe - mas houve leve preferência pela fenda dupla, protótipo de dualidade onda-partícula mais trabalhado nos textos didáticos. Os sistemas são totalmente equivalentes (OSTERMANN, PRADO e RICCI, 2006), mas o IMZ torna mais clara a discussão 'por qual caminho rumou o fóton', por exemplo.

\section{Q.6}

a) M-Z: pelo padrão de interferência, bá regiöes de probabilidade de encontrar o elétron (interferência construtiva) e regiões de interferência destrutiva, onde o elétron não é encontrado, por isso probabilística (Ca; Tt; Z); M-Z: só para um grande número de fótons ocorre o caráter ondulatório (Pl); Fenda dupla: somente após um grande número de fótons atingir o alvo é que percebemos que bouve interferência (Cl; Ls; Ma; Mr); Fenda dupla: bá regiōes de probabilidade de máximos e de mínimos em que a partícula pode ser detectada ao longo da realização das medidas. Essas regiões são determinadas (E; Lz); M-Z: ao se colocar um detector e para um grande número de medidas, a probabilidade é de 50\% para cada braco....(Ra)

Síntese da Q.6 a: a maioria reconheceu que a idéia da FQ como probabilística está na concepção de que "não podemos determinar onde 'um' fóton irá chegar, mas podemos afirmar que existem zonas com maior probabilidade de encontrá-lo". Por outro lado, foi difícil analisar a resposta de $\mathrm{Pl}$, por exemplo. Ele pode ter interpretado que apenas no coletivo há o comportamento ondulatório, esquecendo-se que um elétron interfere consigo mesmo. Talvez sua intenção fosse dizer que só num ensemble de medidas podemos visualizar o padrão de interferência. A imprecisão de linguagem foi tema recorrente nas avaliações durante o semestre. 'Não foi bem isso que en quis dizer? foi uma frase muitas vezes repetida pelos estudantes. 
Investigando a aprendizagem de professores de Física...

b) M-Z: colocando-se um detector em um dos braços, a função de onda colapsa e sabemos por qual dos braços ela passou; há a destruição do padrão de interferência, uma vez que a partícula perde sua característica ondulatória e passa a se comportar como partícula (Ra; Ag); M-Z: usando um detector em um dos braços - quando é sabido o caminho que o objeto quântico irá percorrer (Mr; Ma; Lz; $\mathrm{Ca}$ ), este assume comportamento de particula e o comportamento ondulatório desaparece.... (Ls; E); M-Z: com um polaróide em um dos braços se destrói o padrão de interferência - quando tentamos faz̧er uma medida a função de onda se colapsa em um dos possiveis auto-estados...e vamos ter a particula sempre naquele auto-estado para possiveis medidas de posição não há mais evolução temporal (Tt); Não, pois no momento da deteçãa sabemos na tela exatamente a posição da partícula (Ro); $O$ princípio da incerteza é o limite - se conheço bem Dx, isso provoca grande dispersão no atributo momento (Mu); Sim - elétrons podem nem chegar ao alvo ao serem "colididos" com fótons. O padrão de interferência é cada vez mais destruido - há uma mistura de pontos aleatórios no alvo com a figura de interferência $(\mathrm{Cl})$.

Síntese da Q.6 b: a maioria interpretou corretamente em que situações destruímos o padrão de interferência. Dois alunos deram respostas incorretas (Ro e Mu) especificamente em relação à questão e um aluno $(\mathrm{Tt})$ pareceu ainda não ter uma idéia muito clara do problema, fazendo menção errada em relação à subseqüente evolução temporal.

c) M-Z: não, para cada fóton que chega no anteparo podemos definir sua posição, mas para vários experimentos idênticos forma-se o padrão de interferência e o comportamento é ondulatório, portanto não podem ser partículas convencionais (Ca); Quando bá detecção puntiforme de um objeto quântico, podemos dizer que o objeto aí comporta-se como um objeto clássico. Depois de haver uma deteção deste tipo, a imprecisão do momento tende a infinito (Cl); M-Z: a partícula é detectada por um detector, em um dos braços do aparelho. Se ela passar por outro braço e ali não tiver detector, ela atinge a tela em um ponto localizado (E); Fenda dupla: para um número pequeno de elétrons a característica corpuscular é detectada, contudo quando esse número aumenta percebe-se um padrão de interferência.... O elétron se apresenta como onda ou partícula dependendo do arranjo experimental (Ls); Afirmação incorreta: na fenda dupla, quando há detecção ela é puntiforme, mas a medida em que o número de elétrons detectados aumenta percebe-se um padrão de interferência (Lz; Mu; Ra); M-Z: os polaróides determinam a posição de uma partícula a partir de suas características ondulatórias, ou seja, não convencionais (Ma); fenda dupla: fica fácil observar isso no anteparo, ou com um detector ou com um contador...(Mr).

Síntese da Q.6 c: no entendimento da detecção pontual de objetos quânticos, a maioria deu exemplos ou explicações a partir do IMZ. Apenas um aluno respondeu erradamente $(\mathrm{Cl})$, o qual tem uma noção equivocada sobre a Relação de Incerteza de Heisenberg. Os alunos entenderam o problema da medida e do conseqüente colapso do estado em um dos auto-estados possíveis que compõem a superposição.

d) M-Z: colocando um detector em um dos braços nunca ocorre a detecção das particulas em ambos os braços, mostrando que ocorreu um colapso do estado de superposição em um dos estados - braço A ou braço $B$ - de maneira aleatória, o que confere um caráter indeterminista (Ra; Ro; Lz; Ls; Ca); Não: a MQ tem caráter determinista e é a equação. de onda e a densidade de probabilidade que confere 
ao sistema os possiveis auto-estados (Mu); Fenda única: colocando-se uma lâmpada frente a fenda, verifica-se que alguns objetos que encontram fótons colapsam, mostram por onde passam e outros objetos continuam interferindo (Mr); Fenda dupla: coloca as partículas em uma superposição de auto-estados e a medida no anteparo mostra apenas um dos auto-estados que a partícula se encontrava (E); Sim: porém quando bá este colapso, a MQ é "determinista" somente em prever que não é possivel colapsar em determinados lugares. Podemos não saber em qual das franjas de interf. irá aparecer um objeto quântico, porém será em uma das franjas $(\mathrm{Cl})$.

Síntese da Q.6 d: na compreensão do processo de medida em FQ, a maioria se reportou ao IMZ, 11 com explicações corretas (ex. Ra; Ro; Lz; Ls; Ca). Três alunos responderam erradamente ou de forma confusa ( $\mathrm{Mu}, \mathrm{Mr}$ e E). Houve certa fragilidade nas respostas quando se referiram aos auto-estados e tendência de confundir estado com auto-estados. Discutiu-se auto-estados para o poço infinito, mas em situações mais gerais. A matemática foi fator limitante para as discussões.

\section{Q.12}

Dualista-positivista (Ra; Tt; Pl; Ma; Lz; Ls; E; Ca ); Interpretação ondulatória (Ro); Muitos mundos (Mr); Interpretação da dualidade onda-partícula (Ag)

Síntese da Q.12: a maioria (oito estudantes) elegeu a Ortodoxa como a interpretação de sua preferência. Três não responderam e um respondeu de forma confusa (Ag).

Essa preferência pela interpretação ortodoxa é de certo modo surpreendente, mas também bastante razoável. O primeiro contato dos alunos com as diferentes interpretações da MQ (aula IV) foi notavelmente interessante. Nenhum conhecia outra interpretação que não a ortodoxa e não sabiam nem mesmo que a ela é uma das escolas de interpretação da MQ. Os comentários externavam um certo alívio no sentido de que todos os problemas de entendimento da MQ estariam, então, resolvidos, pois na dificuldade de interpretar de uma maneira haveria outra opção perfeitamente viável. No entanto, à medida que as aulas prosseguiram a exigência de coerência e a dificuldade de interpretar as diferentes situações simuladas pelo IMZ e pela fenda dupla direcionou a maioria dos alunos para a interpretação ortodoxa novamente - uma escolha pela mais pragmática das interpretações.

$\mathrm{Na}$ abordagem do fenômeno, o software teve um papel decisivo, uma vez que proporcionou clara visualização das interferências clássica e quântica, estabelecendo uma ponte entre grandezas macroscópicas e conceitos abstratos, tal como a probabilidade. Muitos alunos, inclusive, responderam ao questionário final citando sistematicamente resultados obtidos nas simulações com o software, mesmo quando a questão proposta não fazia referência alguma ao experimento virtual. A visualização proporcionada pelo software, integrada à discussão teórica realizada conjuntamente, favoreceu, em muito, a compreensão dos alunos acerca do fenômeno e também do funcionamento do arranjo experimental empregado em interferometria. O uso do software aparentemente também acabou favorecendo a aceitação, por parte dos estudantes, da interpretação ortodoxa (Copenhague). 
Investigando a aprendizagem de professores de Física...

\section{Discussão dos resultados}

A análise das respostas ao questionário inicial revelou que o grupo investigado era bastante heterogêneo, embora apenas um fosse formado em Matemática e todos os outros licenciados em Física. Nenhum dos alunos manteve coerência entre as respostas ou demonstrou domínio satisfatório do fenômeno ondulatório para a luz. Eles conseguiam usar os termos dualidade onda-partícula, franjas de interferência, superposição de ondas, mas sem domínio seguro da fenomenologia. A falta de compreensão da fenda dupla clássica demonstrada nas respostas da questão 7 foi crítica e evidenciou uma das razões pela qual os alunos têm dificuldade em aprender FQ. Um resultado importante para a discussão sobre o processo ensino-aprendizagem de conceitos de FQ foi a constatação de que mesmo a fenomenologia da Física Clássica (em particular o paradigma ondulatório) era ainda pouco dominada por esse grupo de professores, merecendo, portanto, adequada abordagem didática. Do ponto de vista do referencial adotado, isso significa que o ensino de FQ está comprometido se os conhecimentos prévios em óptica ondulatória não estão devidamente consolidados.

Em todas as questões analisadas no questionário final, o número de acertos foi sempre maior que o número de respostas erradas ou de itens não respondidos. Os alunos demonstraram domínio incomparavelmente melhor do fenômeno ondulatório, da dualidade onda-partícula e da conseqüente superposição de estados na MQ. Verificou-se, por exemplo, que os alunos $\mathrm{Ra}$, $\mathrm{Ca}$ e $\mathrm{Z}$ responderam corretamente e de forma coerente a todas as questões analisadas, em contraposição à situação do questionário inicial. Houve, ainda, certa dificuldade com a redação ou imprecisão de linguagem, mas apenas três, dos 14 alunos não conseguiram os requisitos mínimos para aprovação na disciplina (Mu, Ro e $\mathrm{Cl})$.

Sobre as interpretações da FQ, um resultado a ser destacado foi a preferência demonstrada pelos alunos pela interpretação de Copenhague, o que poderia sugerir que os experimentos virtuais, por serem tipo "bancada virtual", favorecem a compreensão mais pragmática dada por essa interpretação (a de que a montagem do arranjo experimental determina o "comportamento" observado para o fóton). Esse resultado não trivial ${ }^{8}$ pode delinear um novo objeto de estudo para a pesquisa em ensino de FQ, no sentido de apontar a relevância de se investigar em que medida experimentos virtuais podem favorecer determinadas interpretações da FQ.

\footnotetext{
${ }^{8}$ Essa questão foi levantada pelo professor Olival Freire Jr. (UFBa), na sessão de comunicação oral em que parte desta pesquisa foi apresentada. Ele ressaltou que este resultado difere do que há relatado na literatura em relação ao ensino de FQ nos moldes tradicionais.
} 


\section{Conclusão}

Apresentou-se uma análise qualitativa comparando respostas de dois questionários respondidos no primeiro e no último dia de aula de uma disciplina de Tópicos em Física Moderna e Contemporânea para professores do Ensino Médio. As sínteses das questões e trechos das respostas dos alunos evidenciam aspectos de uma evolução conceitual em tópicos introdutórios de FQ, especialmente as respostas da questão 6 do segundo questionário. Listam-se, agora, alguns fatores que acredita-se terem sido determinantes para esse aprendizado: i) o uso de softwares educacionais, acompanhados de roteiros para utilização e questões a serem respondidas. Os roteiros, se elaborados adequadamente, guiam os alunos para explorar todas as potencialidades do software e, também, situações que não poderiam antecipar por falta de domínio do conteúdo; ii) a apresentação de diferentes interpretações da FQ como recurso para estabelecer, em alicerce firme, as bases da FQ. Aos alunos é apresentada uma distinção clara entre o que é o formalismo da FQ e o que são as interpretações da FQ. A discussão do Postulado das probabilidades de Max Born, a problemática da dualidade onda-partícula e o colapso da função de onda são tópicos nos quais as interpretações aliadas aos softwares educacionais enriquecem as discussões. É notável o número de referências ao software do IMZ e à fenda dupla nas respostas das questões do segundo questionário. A fenda dupla é cânone para a dualidade onda-partícula nos livros-textos, mas o IMZ não; iii) discussões conceituais acompanhadas do formalismo, sempre que possível. Nessa quarta etapa do projeto, mais Matemática foi introduzida no módulo conceitual, evitando a ruptura tão acentuada de semestres anteriores.

Deve-se observar, ainda, que o presente artigo faz parte de um projeto mais amplo e que ainda está em andamento, embora não em fase inicial. O software usado (também desenvolvido no âmbito do projeto) revelou ter, de fato, grande potencial para promover a aprendizagem significativa da interferometria quântica. Do ponto de vista de pesquisa, a implementação desse objeto de aprendizagem em situações de sala de aula suscitou outras tantas questões, que estão sendo também investigadas. 
Investigando a aprendizagem de professores de Física...

\section{Referências}

BRASIL. Orientações curriculares para o Ensino Médio: Ciências da Natureza, Matemática e suas tecnologias. Brasília: Ministério da Educação, Secretaria de Educação Básica, 2006. v. 2.

BRASIL. PCN+ Ensino Médio: orientações educacionais complementares aos parâmetros curriculares nacionais. Brasília: Ministério da Educação, 2002.

BRISCOE, C. The dynamic interactions among belief, role methaphores and teaching practices. A case study of teacher change. Science Education, Salem, Massachussets, v. 75, n. 2, p. 185-199, 1991.

GIL, D. P.; SOLBES, J. The introduction of modern physics: overcoming a deformed vision of science. International Journal of Science Education, Londres, v. 15, n. 3, p. $255-260,1993$.

LEMKE, J. L. Articulating communities: sociocultural perspectives on Science Education. Journal of Research in Science Teaching, Nova York, v. 38, n. 3, p. 296-316, 2000.

MÜLLER, R.; WIESNER, H. Teaching quantum mechanics on an introductory level. American Journal of Physics, Melville, v. 70, n. 3, p. 200-209, 2002.

OSTERMANN, F.; RICCI, T. F. Conceitos de física quântica na formação de professores: relato de uma experiência didática centrada no uso de experimentos virtuais. Caderno Brasileiro de Ensino de Física, Florianópolis, v. 22, n. 1, p. 9-35, 2005.

.; ___ Construindo uma unidade didática conceitual sobre mecânica quântica: um estudo na formação de professores de física. Ciência \& Educação, Bauru, v. 10, n. 2, p. 235-257, 2004.

; PRADO, S. D. Interpretações da mecânica quântica em um interferômetro virtual de Mach-Zehnder. Revista Brasileira de Ensino de Física, São Paulo, v. 27, n. 2, p. 193-203, 2005.

OSTERMANN, F.; PRADO, S. D.; RICCI, T. F. Desenvolvimento de um software para o ensino de fundamentos de Física Quântica. Física na Escola, São Paulo, v. 7, n. 1, p. 22-25, 2006.

PESSOA JR., O. Conceitos de Física Quântica. São Paulo: Livraria da Física, 2003.

PORLÁN, R.; RIVERO, A. El conocimiento de los profesores. Sevilla: Díada, 1998.

REZENDE, F.; OSTERMANN, F. A prática do professor e a pesquisa em ensino de Física: novos elementos para repensar essa relação. Caderno Brasileiro de Ensino de Física, Florianópolis, v. 22, n. 3, p. 316-337, 2005.

RICCI, T. F.; OSTERMANN, F. Uma introdução conceitual à Mecânica Quântica para professores do Ensino Médio. Porto Alegre: Instituto de Física da UFRGS, 2003. (Textos de Apoio ao Professor de Física, n. 14). 
Ostermann, F.; Prado, S. D.; Ricci, T. S. F.

.; __ PRADO, S. D. O tratamento clássico do interferômetro de MachZehnder: uma releitura mais moderna do experimento da fenda dupla na introdução da física quântica. Revista Brasileira de Ensino de Física, São Paulo, v. 29, n. 1, p. 79-88, 2007.

VYGOTSKY, L. S. Pensamento e linguagem. 2. ed. São Paulo: Martins Fontes, 1989.

A formação social da mente: o desenvolvimento dos processos psicológicos superiores. São Paulo: Martins Fontes, 1984.

WERTSCH, J. V. Voces de la mente, un enfoque sociocultural para el estudio de la acción mediada. Madrid: Visor, 1991.

ZEICHNER, K. M. Para além da divisão entre professor-pesquisador e pesquisador acadêmico. In: GERALDI, C. M. G.; FIORENTINI, D.; PEREIRA, E. M. A. (Orgs.). Cartografias do trabalho docente. Campinas: Mercado de Letras, 1998. p. 207-236.

Artigo recebido em agosto de 2006 e aprovado em junho de 2007. 